\title{
Relationship between the polymorphism in the interleukin 1- $\beta$ and the treatment time of patients subjected to a modified piezocision technique
}

\section{Relación entre el polimorfismo en la interleucina $1-\beta$ y el tiempo de tratamiento de pacientes sometidos a una técnica de piezocisión modificada}

\author{
Juan Fernando Aristizábal ${ }^{1}$, Héctor Rios $^{2}, \operatorname{Diego~Rey}^{3}$, María Antonia Álvarez $^{3}$, \\ Beatriz Parra ${ }^{4}$, Mario Ortiz ${ }^{5}$ \\ juan.aristizabal@correounivalle.edu.co
}

1 Universidad del Valle, Facultad de Salud, Escuela de Odontología, Departamento de Ortodoncia, Cali. Colombia. 2 University of Michigan, School of Dentistry, Department of Periodontics and Oral Medicine. Michigan, USA, 3 Universidad CES, Facultad de Odontología, Departmento de Ortodoncia. Medellin, Colombia. , Universidad CES, 4 Universidad del Valle, Facultad de Salud, Escuela de Ciencias Básicas, Departamento de Microbiología. Cali. Colombia 5 Universidad del Valle, Facultad de Salud, Escuela de Ciencias Básicas, Departamento de Morfología, Cali. Colombia

Citation: Aristizábal JF, Rios $\mathrm{H}$, Rey D, Álvarez MA, Parra B, Ortiz M. Colomb Med (Cali). 2020; 51(1): e4141. http://doi.org/10.25100/ cm.v51i1.4141

Received : 10 Dec 2019

Revised : 18 Feb 2020

Accepted : 25 Feb 2020

Published: 28 Mar 2020

Keywords:

Cytokines, Interleukin-1beta, Orthodontic Tooth Movement, Single Nucleotide Polymorphism

Palabras clave:

Citoquinas, Interleucina-1beta, Movimiento del diente de ortodoncia, Polimorfismo de un solo nucleótido

Copyright: (c) 2020 Universidad del Valle.

(c) $(1)$

\section{Abstract}

\section{Aim:}

We aimed to evaluate the correlation between the polymorphism of the interleukin 1-Beta (IL1- $\beta,+3954 \mathrm{C}>\mathrm{T})$ and tooth movement, in a group of Colombian patients undergoing surgically accelerated orthodontic tooth movement.

\section{Methods:}

The study was nested to a controlled clinical trial. Blood samples were taken from 11 women and 29 healthy Colombian male volunteers between 18 and 40 years old, after 1 year of starting orthodontic treatment. The patients presented malocclusion class I, with grade II or III. To detect the genetic polymorphism of the nucleotide $+3954 \mathrm{C}$ to $\mathrm{T}$ in the IL-1 $\beta$ gene, we used a real-time PCR assay.

\section{Results:}

Eleven individuals presented the allele $2(\mathrm{~T})$ heterozygous with the allele $1(\mathrm{~T} / \mathrm{C})$ and 19 individuals were homozygous for the allele $1(\mathrm{C} / \mathrm{C})$. When analyzing the presence of the SNP, no significant differences were found in any of the variables. The best treatment was reflected in Group 3 (selective upper and lower alveolar decortication and 3D collagen matrix) and Group 4 (only selective alveolar decortication in the upper arch, with 3D collagen matrix), with $27 \%$ and $35 \%$ more speed respectively than in the control group.

\section{Conclusions:}

Our analyses indicated that a reduction in the total treatment time can be mostly potentiated by using decortication and collagen matrices and not for the presence of the allele 2 in the IL-1 $\beta$. Nevertheless, it is important that further studies investigate if the polymorphism could be associated with the speed of tooth movement and analyze the baseline protein levels. 
Conflict of Interest:

None

Corresponding author:

Juan Fernando Aristizabal. Department of Orthodontics, Universidad del Valle, Cali. Colombia. Cra 100 \# 11-60 of 505, Tel (57) (2) 3315899, Mail: juan.aristizabal@ correounivalle.edu.co

Clinical Trials registration number: NCT02866929

\section{Remark}

\section{1)Why was this study conducted?}

Given that different patients may have different results in the treatment time, depending on the genetic composition they have, it is relevant to evaluate the interaction between the acceleration techniques and the genotype of patients.

\section{2) What were the most relevant results of the study?}

Our results showed that the use of decortication and collagen matrices allowed a reduction in the total treatment time, while the presence of the allele 2 in the IL- $1 \beta$ had no effect.

\section{3) What do these results contribute?}

Our findings contribute to have a clearer vision of the alternatives that can favor a shorter treatment time in orthodontics.

\section{Resumen}

\section{Objetivo:}

Evaluar la correlación entre el polimorfismo de la interleucina 1-Beta (IL1- $\beta,+3954$ C> T) y el movimiento de los dientes, en un grupo de pacientes colombianos sometidos a un movimiento dental ortodóncico acelerado quirúrgicamente.

\section{Métodos:}

Este fue un estudio secundario derivado de un ensayo clínico aleatorio controlado. Se tomaron muestras de sangre de 11 mujeres y 29 voluntarios varones colombianos sanos entre 18 y 40 años, después de 1 año de comenzar el tratamiento de ortodoncia. Los pacientes presentaron maloclusión clase I, con grado II o III. Para detectar el polimorfismo genético del nucleótido $+3954 \mathrm{C}$ a T en el gen IL-1 $\beta$, se usó un ensayo de PCR en tiempo real.

\section{Resultados:}

11 individuos presentaron el alelo $2(\mathrm{~T})$ heterocigoto con el alelo $1(\mathrm{~T} / \mathrm{C})$ y 19 individuos fueron homocigotos para el alelo $1(\mathrm{C} / \mathrm{C})$. Al analizar la presencia del SNP, no se encontraron diferencias significativas en ninguna de las variables. El mejor tratamiento se reflejó en el Grupo 3 (decorticación alveolar superior e inferior selectiva y matriz de colágeno 3D) y el Grupo 4 (solo decorticación alveolar selectiva en el arco superior, con matriz de colágeno $3 \mathrm{D}$ ), con un $27 \%$ y un $35 \%$ más de velocidad, respectivamente, que en el grupo de control.

\section{Conclusiones:}

Los análisis indicaron que una reducción en el tiempo total de tratamiento puede potenciarse principalmente mediante el uso de decorticación y matrices de colágeno y no por la presencia del alelo 2 en la IL-1 $\beta$. Sin embargo, es importante que otros estudios investiguen si el polimorfismo podría estar asociado con la velocidad del movimiento de los dientes y analizar los niveles de proteína de referencia. 


\section{Introduction}

During the orthodontic induced dental movement, a series of biological phenomena involving complex molecular reactions of the alveolar bone, the periodontal ligament (PDL), the gingiva, the vascular component and the neural networks are induced ${ }^{1}$.

Mechanotransduction initiates inflammation-like events that trigger osteoclastic and regional osteoblastic activity. This activity leads to bone resorption and apposition for expressing tooth movement through modeling-remodeling of the alveolar bone ${ }^{2}$. This biological response is the product of molecular events that involve the synthesis and local release of several biomarkers and cytokines that trigger an inflammatory response, causing a favorable microenvironment for bone remodeling ${ }^{3,4}$.

Previous studies have shown that the response of the periodontal tissue upon orthodontic forces can vary among individuals according to individual specific genetic characteristics. The polymorphism of the pro-inflammatory cytokine Interleukin 1 (IL-1) is one of the currently known determining factors for this inter-subject variation ${ }^{5}$. IL1 is a polypeptide produced mainly by cells of the mononuclear phagocytic lineage ${ }^{6}$ that has two variants: alpha and beta. Interleukin 1 beta (IL-1 $\beta$ ) is believed to be more potent for bone resorption and inhibition of bone formation ${ }^{7}$. This protein is a product of the IL1 gene cluster and has two alleles; the presence of the allele 2 has been related to severity of chronic periodontitis and other medical conditions. Studies of single nucleotide polymorphisms (SNP), show regional and ethnic differences in allelic frequencies for IL- $1 \beta$ alleles ${ }^{8,9}$ signaling that action of IL- $1 \beta$ can be geographically variable. In addition, Isola et al. ${ }^{10}$, reported that individuals with periodontitis + Ischemic heart disease have a decreased level of serum and salivary vitamin $C$ and antioxidant levels in comparison with healthy individuals, suggesting their possible usefulness as biomarkers. According to the authors, vitamin $\mathrm{C}$ modulates an anti-inflammatory response against periodontopathic bacteria involved in periodontitis.

The positive genotype for IL-1 $\beta$ (+3954) has been reported for having a significant effect during dental movement. This genotype occurs when there is at least one polymorphism in one of the two alleles for this cytokine, participating as a biologically active agent in modeling and remodeling bone during orthodontics ${ }^{11}$. In previous studies, the average activity index (AI) of cytokine levels IL-1 $\beta$ / interleukin 1 receptor antagonist (IL1RN) ${ }^{12}$ and the speed of tooth movement were positively related to the increase in IL-1 $\beta$ in experimental sites and was advantageous for a faster dental movement ${ }^{5,13,14}$. However, it remains unknown whether this advantage can be ethnic-related or if the effect of this polymorphism changes with the use of accelerated tooth movement techniques.

The surgical acceleration of dental movement has gained power and interest during the last 10 years ${ }^{15,16}$. The most used techniques include block alveolar movement and alveolar decortication. The last one uses the tissue injury to induce the Regional Acceleration Phenomenon (RAP), which consists of a series of local biochemical changes that trigger and promote an increase in blood flow of the alveolar bone during the process of scarring with stimulation, increasing bone remodeling ${ }^{16}$. This process has been described as the biological basis of accelerated movement in orthodontics ${ }^{17}$. A recent approach for the previous described process, piezocision ${ }^{17}$, combines microincisions in the gingiva with tunneling, allowing the grafting of hard or soft tissues and the piezoelectric decortication of the bone ${ }^{18,19}$. This approach, accelerates the speed of orthodontic dental movement with minimal discomfort and great patient acceptance, and allows increasing the potential for reinforcement of the periodontal phenotype thanks to the addition of bone and/or soft tissue grafts ${ }^{20}$. Moreover, with this technique, the surgeon can safely and precisely, carry out the bone surgery ${ }^{21}$. Likewise, 3D collagen matrix of porcine origin represents a promising alternative to protect and restore a favorable periodontal biotype and promoting the regenerative processes of the mucogingival complex, with a favorable angiogenic support that minimizes the risk of adverse effects with aesthetically appropriate appearance ${ }^{22-24}$. 
Despite the advantages described in literature for the piezocision technique, is possible to think that in a population, different patients may have different results in the treatment time, depending on the genetic composition they have. If we think on the polymorphism of the IL-1 $\beta$, patients may express different results if they carry at least one copy of allele 2 . In this context, it seems relevant to evaluate the interaction between the acceleration techniques and the genotype of patients, in order to have a clearer vision of the alternatives that can favor a shorter treatment time in orthodontics. For these reasons, we aimed to evaluate the correlation between the polymorphism of the IL-1 $\beta$ (IL1- $\beta,+3954$ C > T) and orthodontic dental movement speed, in a group of Colombian patients undergoing surgically accelerated orthodontic tooth movement, using a modified piezocision protocol.

\section{Materials and Methods}

The study was nested to a controlled clinical trial 'A periodontal biotype enhancing strategy for the patient undergoing accelerated orthodontics', which was registered on ClinicalTrials. gov (registration number: NCT02866929). Blood samples were taken from all participating after 1 year of starting orthodontic treatment. The inclusion criteria were healthy volunteers between 18 and 40 years-old, with periodontal stability, with malocclusion class I, with grade II or III crowding according to the Little Irregularity Index, with no more than two millimeters of keratinized gingiva in at least two sites of the lower anterior region and that required orthodontic treatment. The initial sample were 11 women and 29 healthy male volunteers. We excluded patients who had recessions of marginal tissues in lower anterior segment, metabolic diseases or neoplastic alterations, who had orthopedic surgery or fractures in the last six months, with a history of use of bisphosphonates or who were systemically compromised.

Orthodontists were calibrated with the standardized protocol of the passive self-ligation Damon technique. The participants were randomly distributed into four intervention groups, assigning 10 participants to each group. Group 1 being the control treatment group; Group 2 , treatment with selective upper and lower alveolar decortication; Group 3, treatment with selective upper and lower alveolar decortication and 3D collagen matrix of porcine origin in the lower interincisal region; and Group 4, treatment with selective upper alveolar decortication and 3D collagen matrix of porcine origin, without lower alveolar decortication. Out of the total sample, three patients were excluded due to a diagnostic error in the selection of the malocclusion, one from Group 1 and two from Group 4. Each participant was chosen for a certain group by drawing lot, done by the corresponding author. The researcher who performed all the measurements was blinded to the group assignment. The study was blinded concerning the statistical analysis: blinding was obtained by eliminating from the elaboration file every reference to patient group assignment. Volunteers gave informed consent and their rights were protected according to the research protocol of the randomized controlled clinical trial approved by the Human Ethics Committee Act 86 of October 13, 2015. For the blood samples of the patients, an informed consent was prepared and signed by all the study participants and supported through the Human Ethics Committee Act. 105 of April 3, 2017.

The total treatment time was registered in days, according to the time elapsed from the brackets bonding appointment with placement of the first archwire of alignment, until the brackets removal. The fulfillment of the treatment objectives was verified according to occlusal parameters and standardized results. The process was approved unanimously by three of the orthodontists involved in the original clinical trial. The total alignment time was calculated in days according to the time elapsed from the setting of the first archwire cooper Ni-Ti 0.014 inch to the setting of the Titanium-Molybdenum Alloy (TMA) archwire of 0.017x0.025 inch, approved unanimously by three of the orthodontists involved in the original clinical trial. 


\section{Laboratory Procedures}

Whole blood samples obtained with Ethylenediamine tetraacetic acid (EDTA) were divided into 300 $\mu \mathrm{L}$ aliquots and preserved at $-80^{\circ} \mathrm{C}$ for the subsequent DNA extraction ${ }^{25,26}$. The DNA was isolated using an aliquot of $300 \mu \mathrm{L}$ of whole blood using the Quick DNA miniprep plus kit (Zymo D4068).

To detect the genetic polymorphism of the nucleotide +3954 , which exhibits a change from $\mathrm{C}$ to $\mathrm{T}$ in the IL-1 $\beta$ gene, we used a pre-engineered real-time PCR assay TaqMan genotyping SNP for IL-1 $\beta$ (rs1143634) from Applied Biosystems (ABI) ${ }^{27}$. For the real-time PCR amplification reaction, the TaqMan Universal PCR Master Mix was used together with the previous test, following the manufacturer's recommendations. The PCR reaction and the allelic discrimination analysis were performed on the ABI 7500 platform ${ }^{28}$, using synthetic oligonucleotides (Ultramer DNA Oligo from the company IDT) as positive controls for each allele and the SDS software for allelic discrimination 7300/7500/7500 Fast.

\section{Data analysis}

The data was analyzed in the statistical package STATA IC version 14.2. Absolute and relative frequencies for the sex and treatment group variables were estimated. In addition, the average time of alignment phase (upper and lower arch) and time required to complete treatment for each group was calculated. For numerical variables, the normal distribution and homogeneity of variances were verified by Shapiro-Wilk and Levene tests respectively. In addition, differences in the treatment times for groups were tested by a one-way analysis of variance (ANOVA) test and Tukey pairwise comparison, for the total treatment time, and a Kruskal-Wallis test for the age and times of upper and lower arcade alignment. Kruskal-Wallis was applied for not normally distributed variables. The T-Student test was performed between averages or treatment time distribution and presence of the IL-1 $\beta$ SNP in case of normality or U-Mann-Whitney test, otherwise (upper arcade alignment). The confidence level was established at $95 \%$ and the level of significance at $5 \%$.

Incidence rates were calculated for each treatment group and evaluating the presence of SNP. In addition, the ratio for incidence rates was calculated to identify the relationship between treatment speed and the aforementioned variables. The Cox regression model was used to find the time-to-event function and knowing if the different treatment and the presence of SNP are predictors for finishing the alignment and treatment. The proportionality assumptions were checked and the Kaplan-Meier analysis and the Logrank test were added to identify differences in the function. The Kaplan-Meier estimates allows for graphical inspecting the probability of finishing the alignment and treatment. These estimates were also made for the upper and lower arch alignment event.

Table 1. Alignment and total treatment time according to the intervention group.

\begin{tabular}{|c|c|c|c|c|c|c|}
\hline Variables & Group $1(n=9)^{*}$ & Group $2(\mathrm{n}=10)^{*}$ & Group $3(n=10)^{*}$ & Group $4(n=8)^{*}$ & Total $(n=37)^{*}$ & $p$ \\
\hline \multicolumn{7}{|l|}{ Alignment phase (days) } \\
\hline Upper Arch $\dagger$ & $179.2 \pm 27.3$ & $98.8 \pm 56.7$ & $137.4 \pm 130.2$ & $156 \pm 68.5$ & $141.2 \pm 83.9$ & 0.01 \\
\hline Lower Arch $\dagger$ & $206.7 \pm 38.4$ & $146.7 \pm 102.2$ & $165.3 \pm 67.2$ & $179 \pm 69.1$ & $409.6 \pm 120.3$ & 0.25 \\
\hline Total Treatment Time (days) $\ddagger$ & $475.3 \pm 98.3$ & $433.0 \pm 152.3$ & $373.9 \pm 115.8$ & $351.1 \pm 65.4$ & $409.6 \pm 120.3$ & 0.12 \\
\hline Minor Treatment Time $(, 30)(\mathrm{n}(\%)) \S$ & $8.0(23.5)$ & $9.0(26.5)$ & $9.0(26.5)$ & $8.0(23.5)$ & $34.0(100.0)$ & 1.00 \\
\hline
\end{tabular}




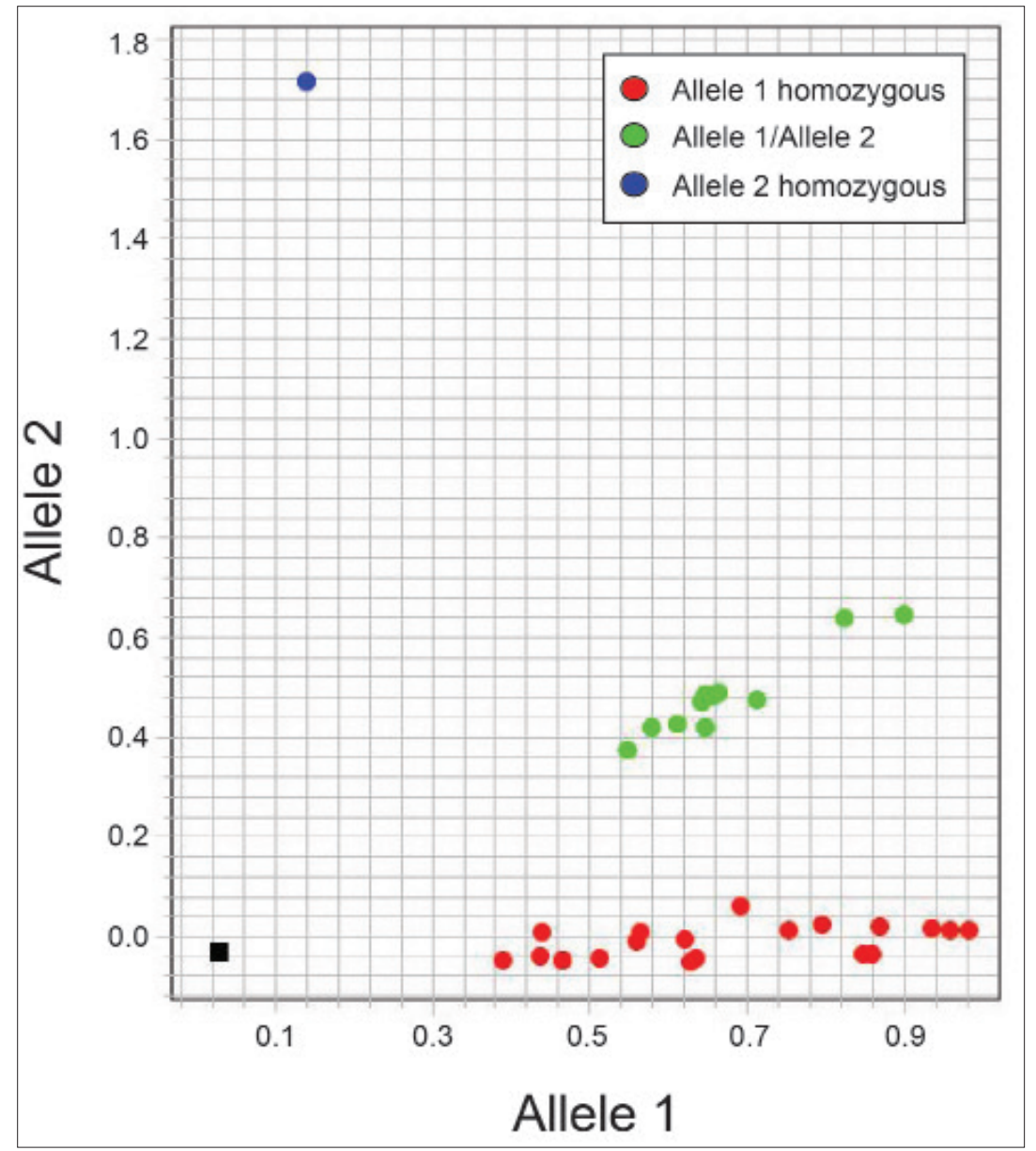

Figure 1. discrimination analysis of SNP $+3954 \mathrm{C}>\mathrm{T}$ in the interleukin 1 beta gene (IL-1 $\beta$ ) shown as scatterplot of Allele 1 (nucleotide $\mathrm{C}$ ) in $\mathrm{x}$-axis versus Allele 2 (nucleotide $\mathrm{T}$ ) in $\mathrm{y}$-axis. Dot colored blue (y-axis) corresponds to the positive control for the Allele 2 homozygous (T/T), dots colored red (x-axis) represent 19 homozygous subjects for the allele $1(\mathrm{C} / \mathrm{C})$ and the positive control, and dots colored green in the diagonal correspond to 11 subjects expressing the SNP $+3954 \mathrm{C}>\mathrm{T}$ in heterozygous manner $(\mathrm{C} / \mathrm{T})$.

\section{Results}

The 40 patients were evaluated and three were excluded due to a diagnostic error in the selection of the malocclusion, which led to management with extractions in one of the cases and the use of additional biomechanics in the remaining two. The results presented here were obtained from the 37 participants who completed the study. Average age of the group was $25.45 \pm 6.23$ years and $29.73 \%$ were women. Average duration of complete orthodontic treatment was estimated at $409.62 \pm 120.29$ days, equivalent to approximately 13 months. (complete statistics in Table $1 \mathrm{~S}$ of supporting material). The average times were statistically the same between the groups, except for the alignment times of the upper $\operatorname{arch}(\mathrm{p}<0.05$, Table 1$)$.

The results of the allelic discrimination analysis (Fig. 1) are expressed in a dot scatter plot of allele 1 (X axis) Versus allele 2 ( $\mathrm{Y}$ axis), where allele 1 corresponds to nucleotide $\mathrm{C}$ and allele 2 corresponds to genetic polymorphism $\mathrm{T}$ in the locus +3954 of IL- $1 \beta$. Samples of homozygous individuals for allele $1(\mathrm{C} / \mathrm{C})$ are grouped in clusters along the $\mathrm{X}$ axis, samples of homozygous individuals for allele $2(\mathrm{~T} / \mathrm{T})$ are grouped along the $\mathrm{Y}$ axis and samples of heterozygous individuals with allele 1 and allele $2(\mathrm{C} / \mathrm{T})$ are grouped on the diagonal. From the 37 subjects evaluated, 11 presented allele $2(\mathrm{~T})$ heterozygous together with allele $1(\mathrm{~T} / \mathrm{C})$ and 19 individuals were homozygous for allele $1(\mathrm{C} / \mathrm{C})$. No subject was homozygous for the SNP (T/T). 
Table 2. Alignment time and total treatment time according to the presence of the SNP.

\begin{tabular}{lrrr}
\hline Variables & Present (n=10) & Absent (n=27) & Total (n=37) \\
\hline Alignment phase (days) & & & \\
Upper Arch & $179.2 \pm 27.3$ & $98.8 \pm 56.7$ & $141.2 \pm 83.9$ \\
Lower Arch & $206.7 \pm 38.4$ & $146.7 \pm 102.2$ & $409.6 \pm 120.3$ \\
Total Treatment Time (days) & $475.3 \pm 98.3$ & $433 \pm 152.3$ & $409.6 \pm 120.3$ \\
Minor Treatment Time (,30) & $8.0(76.5)$ & $26.0(23.5)$ & $34.0(100.0)$ \\
\hline
\end{tabular}

${ }^{*}$ Mean $\pm \mathrm{sd}$

Table 3. Incidence rates for total treatment time and presence of polymorphism.

\begin{tabular}{lcrrrrc}
\hline Group & Time (days) & n & TI & TI - 95\% IC & RTI & RTI - 95\% IC \\
\hline 1 & 4,278 & 9 & 2.1 & $1.1-4.0$ & 1 & \\
2 & 4,330 & 10 & 2.3 & $1.2-4.3$ & 1.1 & $0.4-3.0$ \\
3 & 3,739 & 10 & 2.7 & $1.4-4.9$ & 1.3 & $0.5-3.5$ \\
4 & 2,809 & 8 & 2.8 & $1.4-5.7$ & 1.4 & $0.5-3.9$ \\
Without SNP & 1,054 & 27 & 2.5 & $1.8-3.7$ & 1 & \\
With SNP & 4,613 & 10 & 2.2 & $1.2-4.0$ & 0.9 & $0.4-1.8$ \\
\hline
\end{tabular}

n: number of treatments completed.

TI: Incidence rate $\mathrm{x} 1000$ people-day.

RTI: Reason for incidence rates.

95\% IC: 95\% confidence interval

When analyzing the data according to the presence or absence of the SNP (T/C), without discriminating by groups, no significant differences were found in any of the variables (Table 2). The incidence rate of total treatment time according to the group showed that the treatment with greater efficiency was reflected in Group 3 and Group 4 (Table 3), with 27\% and 35\% more speed respectively than in the control group, however the differences are not statistically significant.

The Cox regression was modeled with the variables "presence of polymorphism" and "treatment group" for the total alignment time (Table 4). This analysis showed that the type of treatment favors the probability of reaching the treatment goal in terms of time ( $\mathrm{HR}=$ 1.36, 95\% CI: 0.96 -1.92), however, these relationships were not statistically significant (Table 4). Moreover, the graphical analysis by Kaplan-Meier (Fig. 2) showed that the absence of the polymorphism is related to a shorter treatment completion time, especially for the upper arch (Fig. 2B); nevertheless, the logrank test showed that the risk functions had no statistically significant differences ( $p$-value $=0.088$ ) and it is not statistically modified when stratifying by treatment $(p$-value $=0.166)$.

All values obtained for estimations of the average time of alignment for the upper and lower arches were analyzed in the same way as the total alignment time (Table 4). The incidence rates showed that the speed is higher in group 2 and group 3 for the case of the upper arch (IR = 10.12146, CI 95\%: 5.445-18.811 and IR: 7.27802, CI 95\%: 3.916-13.526 respectively, Table $2 \mathrm{~S}$ of supporting material). Similar situation occurred for the alignment in the lower arch in groups 2 and 3 (IR $=6,816,95 \%$, CI 3,667-12,669 and IR: 6,049; 95\% CI: 255-11,243, Table 3 S of supporting material). Despite the above, and unlike the general analysis of the total treatment time, the presence of the polymorphism is a factor that is related to higher alignment speed for the upper arch (HR $=1.3,95 \% \mathrm{CI}: 0.587-2.936$, Table 4$)$, not for the lower arch $(\mathrm{HR}=0.870$, 95\% CI: 0.366 - 1.942, Table 4). 
Table 4. Ratio of proportional hazards for total treatment time, upper arch and lower arch alignment

\begin{tabular}{|c|c|c|c|c|c|c|}
\hline Variable & Groups & HR & SE & $\mathbf{z}$ & $p(\mathrm{z})$ & $95 \% \mathrm{CI}$ \\
\hline \multirow{6}{*}{ Total treatment } & SNP & 0.6 & 0.3 & -1.2 & 0.24 & $0.3-1.4$ \\
\hline & Group & 1.4 & 0.2 & 1.8 & 0.08 & $0.9-1.9$ \\
\hline & SNP*Group 1 & 0.6 & 0.2 & -1.3 & 0.18 & $0.2-1.3$ \\
\hline & SNP*Group 2 & 0.9 & 0.5 & -0.1 & 0.89 & $0.4-2.4$ \\
\hline & SNP*Group 3 & 1.4 & 0.7 & 0.6 & 0.55 & $0.5-3.8$ \\
\hline & SNP*Group 4 & 2.5 & 1.3 & 1.8 & 0.07 & $0.9-6.9$ \\
\hline \multirow{6}{*}{ Upper arch } & SNP & 1.3 & 0.5 & 0.7 & 0.51 & $0.6-2.9$ \\
\hline & Group & 1.0 & 0.2 & 0.0 & 0.97 & $0.8-1.3$ \\
\hline & SNP*Group 1 & 1.5 & 0.7 & 1.0 & 0.34 & $0.7-3.5$ \\
\hline & SNP*Group 2 & 2.8 & 1.3 & 2.2 & 0.03 & $1.1-7.2$ \\
\hline & SNP*Group 3 & 2.0 & 1.1 & 1.2 & 0.22 & $0.7-5.7$ \\
\hline & SNP*Group 4 & 1.1 & 0.6 & 0.2 & 0.83 & $0.4-3.2$ \\
\hline \multirow[t]{6}{*}{ Lower arch } & SNP & 0.9 & 0.4 & -0.3 & 0.73 & $0.4-1.9$ \\
\hline & Group & 1.0 & 0.2 & 0.3 & 0.79 & $0.8-1.4$ \\
\hline & SNP*Group 1 & 0.8 & 0.4 & -0.4 & 0.69 & $0.4-1.9$ \\
\hline & SNP*Group 2 & 1.5 & 0.7 & 0.8 & 0.40 & $0.6-3.8$ \\
\hline & SNP*Group 3 & 1.3 & 0.6 & 0.5 & 0.62 & $0.5-3.3$ \\
\hline & SNP*Group 4 & 1.2 & 0.6 & 0.3 & 0.78 & $0.4-3.2$ \\
\hline
\end{tabular}

HR: Hazard ratio

SE: Standard Error

95\% CI: $95 \%$ confidence interval

We considered the presence of the SNP and the group as separated variables, and the combined effects of SNP and groups (SNP* Group).

\section{Discussion}

This study evaluated the correlation between the polymorphism of the IL1- $\beta,+3954$ C > T and orthodontic dental movement speed in patients undergoing surgically accelerated orthodontic tooth movement. Here, we found that a reduction in the total treatment time can be mostly potentiated by using decortication and collagen matrices and not for the presence of the allele 2 in the IL-1 $\beta$. Today more than ever, we have the possibility of studying the relationship between the genetic profile of patients and the effectiveness of treatments. Our exploratory study, with the natural limitations of the sample being nested to a controlled clinical trial in progress, represents the first attempt to correlate polymorphism of IL- $1 \beta$ with patients undergoing surgical acceleration procedures, in terms of alignment time and total orthodontic treatment time. We also evaluated the use of a porcine collagen matrix in non-extraction patients with crowding between two to three according to Little Index, and decreased periodontal biotype in the anterior inferior region.

The prevalence of the positive genotype for IL-1 has been reported in different populations. In Hispanic populations, a prevalence of $26 \%$ has been found, with the presence of allele 2 homozygous for both polymorphisms of interleukin 1 alpha (IL-1 $\alpha)(-889)$ and IL-1 $\beta$ $(+3954)^{29}$. In the Chinese population has been reported a prevalence of only $2.3 \%$ with a positive genotype for this polymorphism ${ }^{8}$. For the European population a prevalence of the positive genotype has been reported in a range of $29-46 \%$ and in the Caucasian population of $29-38 \%{ }^{30,31}$. In the Thai population, a prevalence of $1.6 \%$ was found and the homozygous allele 2 of the IL-1 $\beta(+3954)$ gene was not detected ${ }^{32}$. Their results were similar to those found for the Chinese population, indicating that in Asian population the prevalence of allele 2 in the gene IL-1 $\alpha(-889)$ and IL-1 $\beta(+3954)$ is lower when compared with other ethnic groups ${ }^{32}$. In our study, the prevalence was $27 \%$ for genetic polymorphism of the nucleotide +3954 in the IL-1 $\beta$, similar to the values reported for Hispanic populations.

In general, conventional orthodontic treatment ranges between 18 and 30 months $^{33-35}$. With the technique used for orthodontic treatment in our study, we did not find significant differences between the groups of treatment for most of analyses, but we noticed some general patterns that 


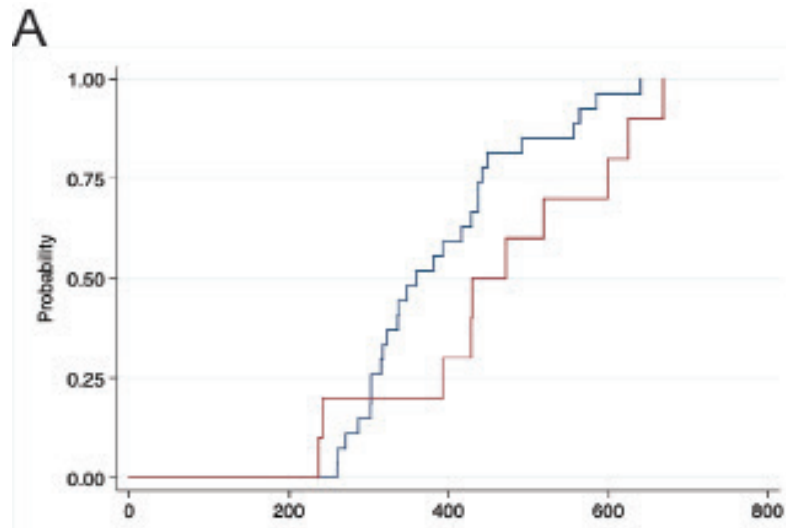

B

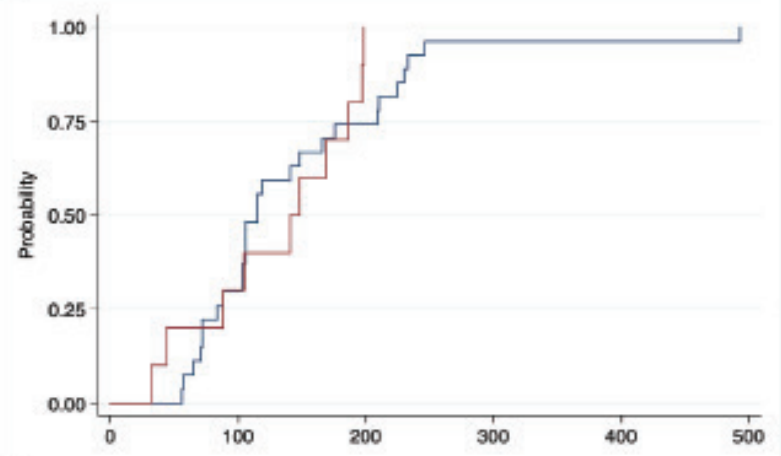

C

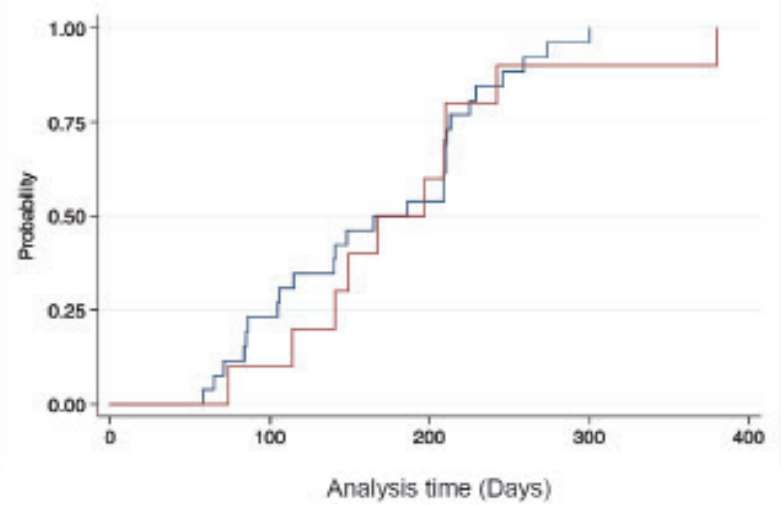

Figure 2. Estimation of the risk function by Kaplan Meier according to the presence / absence of polymorphism for the variables (A) total treatment time, (B) upper arch alignment and (C) lower arch alignment. Blue line: without SNP, Red line: with SNP.

can guide future studies and analyses. We found a reduction in the treatment times for both the upper and lower arch alignment, and for the total treatment time in the three groups with intervention (Table 1). The lowest treatment time when only tooth alignment is considered was found in group 2 (Decortication only) for both the upper and lower arch. In contrast, when considering the overall treatment time, group 4 (only porcine collagen matrix tunneled in position and upper decortication) was the group with the shortest treatment time.

Future studies should assess why different treatments work differentially for the total treatment time and for lower and upper arch alignment times. According to literature, decortication causes shorter times of treatment, faster tooth movement and decrease the risk of root resorption ${ }^{36}$, and according to our results it appears to work better for individual upper and 
lower arches. Furthermore, our results suggest that the best approach for reducing treatment times will depend on the specific area to be treated. If the focus is only on one of upper or lower areas, then decortication appears to be sufficient for a more efficient treatment, without the use of collagen matrices. Although it is true that the results did not show statistically significant differences, they are in agreement with the recent literature, where times of the regional acceleration phenomenon are limited and are also associated with the magnitude of the injury of the bone tissue ${ }^{37-39}$.

We found shorter treatment times than those reported by recent studies for orthodontic treatment times ${ }^{35}$, in $92 \%$ of the sample $(\mathrm{n}=34)$, including 8 of the 9 patients in the control group. These, overall efficient treatment duration times can be partially explained by five factors. The first one compile the surgical interventions in the experimental groups. The second is the overall rigorous protocol and compliance followed by all subjects. The third one is the close follow up and monitoring for all subjects in the study. The fourth is the digital standardized digital treatment planning to determine optimal bracket location, and the fifth involves the calibrated and masked examiners documenting treatment times. The possible advantages offered by the self-ligating technique, could explain the adequate times observed even in the control group (non-surgical) ${ }^{35}$. Atypically, this was the group with the most randomly allocated subjects, where the SNPs were identified in one allele (In this group 4 out of the 9 subjects were heterozygotes for the SNP). Specifically, having at least one copy of allele 2 in IL-1 $\beta(+3954)$, a medium AI, and a low average IL-1RN in GCF at experimental sites has been associated with faster dental movement ${ }^{14}$.

The values of time of alignment and total treatment time for the total sample, without discrimination of the intervention group were greater for patients with the polymorphism, but differences were not statistically significant. Furthermore, in accordance to the other results discussed below, it appears that the type of intervention (treatment groups) weights more than the presence of SNP for a reduction in treatment times, at least in this group of patients and taking into account the limitations of sample size.

The multivariate analysis (Table 4) correlating the presence of polymorphism and treatment group variables, showed that the type of treatment favors the probability of finishing the alignment in less time, the foregoing without statistically significant differences. When relating the SNP to the total treatment time (SNP* Group), the probability of finishing the treatment diminished a $45 \%$ for the control group, $7 \%$ for the treatment group 2, and $35 \%$ and $51 \%$ for groups 3 and 4 respectively. These results could be explained as the potentiation of the biological activation therapy of the experimental groups together with the presence of the polymorphism. However, for the total treatment time, the biological activation therapy has more weight than the SNP. Additionally, as the confidence intervals are very broad, this should be considered with caution.

The Kaplan-Meier estimations confirmed the patterns discussed previously. Despite an initial increase in the speed of treatment for patients with SNP, later the treatment group becomes more relevant than the Polymorphism in the total time of treatment. This is possibly because in the end when the RAP decays, occurs a symbiosis between the SNP and the RAP in the alignment phase that could explain the initial peak of speed. The incidence rates showed that the alignment rates were higher for groups 2 and 3 for both the upper and lower arch. This can be explained as a potentiation effect of a higher therapy impact (Decortication) plus SNP in a limited period of time RAP, due to the extensive cocktail of proinflammatory cytokines at that time including IL- $1 \beta$.

After reviewing the results in detail, it is possible to speculate that the synergy of all molecular activation produced by mechanotransduction, a basal level of pro-inflammatory cytokines IL- $1 \beta$, and the cascade of RAP biological events after selective alveolar decortication, can 
explain the accelerated orthodontic tooth movement seen at the first stage of the treatment. However, all the analyses indicated that a reduction in the total treatment time could be mostly potentiated by using decortication and collagen matrices and not for the presence or absence of the allele 2 in the IL- $1 \beta$.

We also consider imperative to recognize the epigenetic modulation on coding and noncoding chromosomal regions that influence our proteome, resulting on a dynamic molecular effect rather than a static picture of our protein map. Thus, genotyping our patients represent only one piece of this complex puzzle ${ }^{40-45}$. Nonetheless, this type of particular responses associated with the speed of tooth movement, being mediated dynamic genetic characteristics, could generate different functional phenotypes in the population. This will allow us to understand how orthodontics treatments should not only be focused on the technical level, but also be tailored based on a thorough clinical diagnosis framed by a growing understanding of important genetic determinants.

Overall, our analyses indicated that a reduction in the total treatment time can be mostly potentiated by using decortication and collagen matrices and not for the presence of the allele 2 in the IL-1 $\beta$. Future studies should analyze if the polymorphism could be associated with the speed of tooth movement and analyze the baseline protein levels. It is necessary to propose prospective designs with greater sample power that allow drawing conclusions that are more precise. As we mentioned above, this type of genetic studies are only part of a much more complex situation that involves epigenetic factors, nonetheless, they are needed in order to progress in this field of knowledge and have a more integral approach to orthodontic procedures.

\section{References}

1. Krishnan V, Davidovitch Z. On a path to unfolding the biological mechanisms of orthodontic tooth movement. J Dent Res. 2009;88(7):597-608. doi:10.1177/0022034509338914.

2. Yamaguchi M. RANK / RANKL / OPG during orthodontic tooth movement. Orthod Craniofacial Res. 2009;12:113-119. doi: 10.1111/j.1601-6343.2009.01444.x.

3. Ariffin SHZ, Yamamoto Z, Zainol ALZ, Abdul WRM, Ariffin ZZ. Cellular and molecular changes in orthodontic tooth movement. Sci World J. 2011; 11: 1788-803. doi:10.1100/2011/

4. Dolce C, Scott Malone J, Wheeler TT, Al E. Current concepts in the biology of orthodontic tooth movement. Semin Orthod. 2002;8(1):6-12. doi:10.1053/sodo.2002.28165

5. Iwasaki LR, Gibson CS, Crouch LD, Marx DB, Pandey JP, Nickel JC. Speed of tooth movement is related to stress and IL-1 gene polymorphisms. Am J Orthod Dentofac Orthop. 2006; 130(6): 698.e1-9. doi: 10.1016/j. ajodo.2006.04.022

6. Dinarello CA. Interleukin-1 and interleukin-1 antagonism. Blood. 1991; 77(8): 1627-52

7. Stashenko P, Obernesser MS, Dewhirst FE. Effect of immune cytokines on bone. Immunol Invest. 1989;18(14):239-249. DOI: 10.3109/08820138909112240

8. Armitage GC, Wu Y, Wang H, Sorrell J, Giovine FS, Duff GW. Low prevalence of a periodontitis-associated interleukin-1 composite heritage. J Periodontol. 2000;71(2):10-12. doi: 10.1902/jop.2000.71.2.164.

9. Chen H, Wilkins LM, Aziz N, Cannings C, Wyllie DH, Bingle C, et al. Single nucleotide polymorphisms in the human interleukin-1B gene affect transcription according to haplotype context. Hum Mol Genet. 2006;15(4):51929. doi: $10.1093 / \mathrm{hmg} / \mathrm{ddi} 469$.

10. Isola G, Polizzi A, Muraglie S, Leonardi R, Lo Giudice A. Assessment of vitamin C and antioxidant profiles in saliva and serum in patients with periodontitis and ischemic heart disease. Nutrients. 2019;11(12):2956. doi:10.3390/nu11122956 
11. Krishnan V, Davidovitch ZZ. Cellular, molecular, and tissue-level reactions to orthodontic force. Am J Orthod Dentofac Orthop. 2006;129(4):469.e1-32. doi: 10.1016/j.ajodo.2005.10.007

12. Ishihara Y, Nishihara T, Kuroyanagi T, Shirozu N, Yamagishi E, Ohguchi M, et al. Gingival crevicular interleukin-1 and interleukin-1 receptor antagonist levels in periodontally healthy and diseased sites. $\mathrm{J}$ Periodontal Res. 1997;32(6):524-529.

13. Iwasaki LR, Crouch LD, Tutor A, Gibson S, Hukmani N, Marx DB, et al. Tooth movement and cytokines in gingival crevicular fluid and whole blood in growing and adult subjects. Am J Orthod Dentofac Orthop. 2005;128(4):483-91. doi: 10.1016/j.ajodo.2004.03.037

14. Iwasaki L, Chandler J, Marx D, Pandey J, Nickel J. IL-1 gene polymorphisms, secretion in gingival crevicular fluid, and speed of human orthodontic tooth movement. Orthod Craniofac Res. 2009;12:129-140. doi: 10.1111/j.1601-6343.2009.01446.x.

15. Alikhani M, Raptis M, Zoldan B, Sangsuwon C, Lee YB, Alyami B, et al. Effect of micro-osteoperforations on the rate of tooth movement. Am J Orthod Dentofac Orthop. 2013;144(5):639-48. doi:10.1016/j. ajodo.2013.06.017

16. Wilcko WM, Wilcko T, Bouquot JE, Ferguson DJ. Rapid orthodontics with alveolar reshaping: two case reports of decrowding. Int J Periodontics Restorative Dent. 2001;21(1):9-19.

17. Dibart S, Sebaoun JD, Surmenian J. Piezocision: a minimally invasive, periodontally accelerated orthodontic tooth movement procedure. Compend Contin Educ Dent. 2009;30(6):342-350.

18. Dibart S, Surmenian J, Sebaoun JD, Montesani L. Rapid treatment of Class II malocclusion with piezocision: two case reports. Int J Periodontics Restorative Dent. 2010;30(5):487-493.

19. Keser El, Dibart S. Piezocision-assisted Invisalign treatment. Compend Contin Educ Dent. 2011;32(2):4651.

20. Dibart S. Piezocision TM. Accelerating orthodontic tooth movement while correcting hard and soft tissue deficiencies. Front Oral Biol. 2015;18:102-8. doi: 10.1159/000351903.

21. Ramaglia L, Cicciù M, Fiorentino E, Saviano R, Blasi A, Cervino G, et al. Effectiveness of a piezoelectricassisted distraction osteogenesis procedure for the treatment of ankylosed permanent front teeth. $\mathrm{J}$ Craniofac Surg. 2019;30(4):e356-e359. doi: 10.1097/SCS.0000000000005332.

22. Schmitt CM, Neukam FW, Schmitt CM, Wehrhan F, Neukam FW, Schlegel KA. Long-term outcomes after vestibuloplasty with a porcine collagen matrix (Mucograft (r)) versus the free gingival graft?: a comparative prospective clinical trial. Clin Oral Implants Res. 2015; 27(11): e125-e133. doi:10.1111/clr.12575Schmitt CM, Neukam FW,

23. Menceva Z, Dimitrovski O, Popovska M, Spasovski S, Spirov V, Petrusevska G. Free Gingival Graft versus Mucograft: Histological Evaluation. Open Access Maced J Med Sci. 2018;6(4):675-679. doi:10.3889/ oamjms.2018.127

24. Lima RSR, Peruzzo DC, Napimoga MH. Evaluation of the biological behavior of mucograft in human gingival fibroblasts: an in vitro study. Braz Dent J. 2015;26(6):602-606. doi: 10.1590/0103-6440201300238.

25. Jones R, Golding J. Choosing the types of biological sample to collect in longitudinal birth cohort studies. Paediatr Perinat Epidemiol. 2009; 23: 103-113. doi:10.1111/j.1365-3016.2008.01000.x

26. Madisen L, Hoar DI, Holroyd CD, Crisp M, Hodes ME, Reynolds JF. The effects of storage of blood and isolated DNA on the integrity of DNA. Am J Med Genet. 1987;27:379-390. doi:10.1002/ajmg.1320270216

27. Gaedigk A, Freeman N, Hartshorne T, Riffel AK, Irwin D, Bishop JR, et al. SNP genotyping using TaqMan(r) technology: the CYP2D6*17 assay conundrum. Sci Rep. 2015;5:9257. doi: 10.1038/srep09257

28. Kamau E, Alemayehu S, Feghali KC, Tolbert LS, Ogutu B, Ockenhouse CF. Development of a TaqMan Allelic Discrimination assay for detection of single nucleotides polymorphisms associated with anti-malarial drug resistance. Malar J. 2012;11:23. doi: 10.1186/1475-2875-11-23 
Relationship between the polymorphism in the interleukin $1-\beta$ and the treatment time of patients subjected to a modified piezocision technique

29. Caffesse RG, De LaRosa MR, De LaRosa MG, Mota LF. Prevalence of interleukin 1 periodontal genotype in a Hispanic dental population. Quintessence Int. 2002;33(3):190-194.

30. Sakellari D, Koukoudetsos S, Arsenakis M, Konstantinidis A. Prevalence of IL-1A and IL-1B polymorphisms in a Greek population. J Clin Periodontol. 2003;30(1):35-41. doi: 10.1034/j.1600-051X.2003.300106.x

31. Papapanou PN, Neiderud A-M, Sandros J, Dahlé NG. Interleukin-1 gene polymorphism and periodontal status. Clin Periodontol J. 2001;28(5):389-396. doi: 10.1034/j.1600-051x.2001.028005389.x.

32. Anusaksathien $O$, Sukboon A, Sitthiphong P, Teanpaisan R. Distribution of interleukin-1 $B+3954$ and IL-1 a - 889 genetic variations in a thai population group. J Periodontol. 2003;74(12):1796-1802. doi: 10.1902/ jop.2003.74.12.1796.

33. Mavreas D, Athanasiou AE. Factors affecting the duration of orthodontic treatment: A systematic review. Eur J Orthod. 2008;30(4):386-395. doi:10.1093/ejo/cjn018

34. Fink DF, Smith RJ. The duration of orthodontic treatment. Am J Orthod Dentofac Orthop. 1992;102(1):4551. doi:10.1016/0889-5406(92)70013-Z

35. Tsichlaki A, Chin Y, Pandis N, Fleming PS. How long does treatment with fixed orthodontic. Am J Orthod Dentofac Orthop. 2016;149(3):308-318. doi: 10.1016/j.ajodo.2015.09.020

36. Fau V, Diep D, Bader G, Brezulier D, Sorel O. Effectiveness of selective alveolar decortication in accelerating orthodontic treatment: a systematic review. Orthod Fr. 2017;88(2):165-178. doi: 10.1051/ orthodfr/2017005

37. Cohen G, Campbell PM, Rossouw PE, Buschang PH. Effects of increased surgical trauma on rates of tooth movement and apical root resorption in foxhound dogs. Orthod Craniofacial Res. 2010;13(3):179-190. doi:10.1111/j.1601-6343.2010.01494.x

38. Ruso S, Campbell PM, Rossmann J, Opperman LA, Taylor RW, Buschang PH. Bone response to buccal tooth movements - With and without flapless alveolar decortication. Eur J Orthod. 2014;36(6):613-623. doi: 10.1093/ejo/cjt057

39. Buschang PH, Campbell PM, Ruso S. Accelerating tooth movement with corticotomies: is it possible and desirable? Semin Orthod. 2012;18(4):286-294. doi: 10.1053/j.sodo.2012.06.007

40. Hartsfield JKJ, Everett ET, Al-Qawasmi RA. Genetic factors in external apical root resorption and orthodontic treatment. Crit Rev oral Biol Med. 2004;15(2):115-122. doi: 10.1177/154411130401500205

41. Iglesias-Linares A, Yañez-Vico RM, Ballesta-Mudarra S, Ortiz-Ariza E, Mendoza-Mendoza A, Perea-Pérez $\mathrm{E}$, et al. Interleukin 1 receptor antagonist (IL1RN) genetic variations condition post-orthodontic external root resorption in endodontically-treated teeth. Histol Histopathol. 2013;28(6):767-773. doi: 10.14670/HH-28.767.

42. Tomoyasu Y, Yamaguchi T, Tajima A, Inoue I, Maki K. External apical root resorption and the interleukin1B gene polymorphism in the Japanese population. Orthod Waves. 2009;68(4):152-157. doi: 10.1016/j. odw.2009.05.002

43. Borilova Linhartova P, Cernochova P, Kastovsky J, Vrankova Z, Sirotkova M, Izakovicova HL. Genetic determinants and postorthodontic external apical root resorption in Czech children. Oral Dis. 2017;23(1):29-35. doi: 10.1111/odi.12564

44. Wu FL, Wang LY, Huang YQ, Guo WB, Liu CD, Li SG. Interleukin-1ß +3954 polymorphisms and risk of external apical root resorption in orthodontic treatment: A meta-analysis. Genet Mol Res. 2013;12(4):4678-4686. doi: 10.4238/2013.October.18.6

45. Linhartova P, Cernochova P, Izakovicova Holla L. IL1 gene polymorphisms in relation to external apical root resorption concurrent with orthodontia. Oral Dis. 2013;19(3):262-270. doi: 10.1111/j.1601-0825.2012.01973.x 


\section{Supporting Information.}

Table 1S. Distribution of sex and age variables of study participants according to the intervention group. p-values correspond to Kruskal-Wallis test. Values in bold indicate significant differences.

\begin{tabular}{lcccrrr}
\hline & Group 1 $(\mathrm{n}=9)$ & Group 2 $(\mathrm{n}=10)$ & Group 3 $(\mathrm{n}=10)$ & Group 4 (n=8) & Total $(\mathrm{n}=37)$ & $p$ \\
\hline Age (years \pm sd) & $23.77 \pm 5.71$ & $21.10 \pm 3.84$ & $30.10 \pm 6.83$ & $27 \pm 4.40$ & $25.45 \pm 6.23$ & 0.01 \\
Female (n) & $3(33.33)$ & $3(30)$ & $2(20)$ & $3(29.73)$ & $11(29.73)$ & 0.93 \\
Male (n) & $6(66.66)$ & $7(70)$ & $8(80)$ & $5(70.27)$ & $26(70.27)$ \\
SNP (n(\%))† & $4(40)$ & $3(30)$ & $1(10)$ & $2(20)$ & $10(100)$ & 0.42 \\
\hline
\end{tabular}

†Fisher's exact test

Table 2S. Incidence rates of upper arch alignment by treatment and presence of polymorphism

\begin{tabular}{|c|c|c|c|c|c|c|c|}
\hline & Person-time & Aligned (n) & IR & IR - CI 95\% & RIR & RIR - CI 95\% & $p$ \\
\hline \multicolumn{8}{|l|}{ Group } \\
\hline 1 & 1,613 & 9 & 5.58 & $2.90-10.72$ & 1 & & \\
\hline 2 & 988 & 10 & 10.12 & $5.45-18.81$ & 1.81 & $0.66-5.05$ & 0.20 \\
\hline 3 & 1,374 & 10 & 7.28 & $3.92-13.53$ & 1.30 & $0.48-3.63$ & 0.57 \\
\hline 4 & 1,248 & 8 & 6.41 & $3.21-12.82$ & 1.15 & $0.39-3.35$ & 0.78 \\
\hline \multicolumn{8}{|l|}{ SNP } \\
\hline Without SNP & 3,915 & 27 & 6.90 & $4.73-10.06$ & 1 & & \\
\hline With SNP & 1,308 & 10 & 7.65 & $4.11-14.21$ & 1.11 & $0.48-2.36$ & 0.76 \\
\hline
\end{tabular}

IR: Incidence rate $\mathrm{x} 1,000$ people-day,

RIR: Reason for incidence rates.

95\%, CI: 95\% confidence interval

Table 3S. Accumulated incidence rates of lower arch alignment by treatment and presence of polymorphism.

\begin{tabular}{|c|c|c|c|c|c|c|c|}
\hline & Person-time & Aligned failures (n) & IR rate & IR - CI 95\% & RIR & RIR - CI 95\% & $p$ \\
\hline \multicolumn{8}{|l|}{ Group } \\
\hline 1 & 1,860 & 9 & 4.84 & $2.52-9.30$ & 1 & & \\
\hline 2 & 1,467 & 10 & 6.82 & $3.67-12.67$ & 1.41 & $0.51-3.92$ & 0.46 \\
\hline 3 & 1,653 & 10 & 6.05 & $3.26-11.24$ & 1.25 & $0.46-3.48$ & 0.63 \\
\hline 4 & 1,253 & 7 & 5.59 & $2.67-11.72$ & 1.15 & $0.37-3.48$ & 0.77 \\
\hline \multicolumn{8}{|l|}{ SNP } \\
\hline Without SNP & 4,350 & 26 & 5.98 & $4.07-8.78$ & 1 & & \\
\hline With SNP & 1,883 & 10 & 5.31 & $2.86-9.87$ & 0.89 & $0.38-1.90$ & 0.77 \\
\hline
\end{tabular}

IR: Incidence rate $x$ 1,000 people-day,

RIR: Reason for incidence rates.

95\%, CI: 95\% confidence interval 